\title{
VARIANTS OF DEVELOPMENT OF SPORTS CAREER OF 11-YEAR-OLD FEMALE SWIMMERS
}

\author{
Careers of 11-year-old female swimmers
}

\author{
GRZEGORZ BIELEC \\ Gdańsk University of Physical Education and Sport, Department of Swimming
}

\author{
Mailing address: Grzegorz Bielec, Gdańsk University of Physical Education and Sport, \\ Department of Swimming, 1 Górski Street, 80-336 Gdańsk, tel.: +48 608778106, fax: +48 58 3418460, \\ e-mail: pitajlo1@wp.pl
}

\begin{abstract}
Introduction. The development of a sporting career takes a course within a phased manner, the various stages are characterized by different goals and tasks. In competitive swimming there are many cases of athletes who achieved high sporting results in the category of children and youths and who soon after abandoned their interest in training. The aim of this study was to find the association between the sports achievements of 11-year-old girls competing in the $200 \mathrm{~m}$ backstroke events and their sports level in the subsequent years of their career. Material and methods. The results of the sporting careers of girls who ranked from $1^{\text {st }}$ to $20^{\text {th }}$ in the $200 \mathrm{~m}$ backstroke event in the Polish Correspondence Championships for 10 and 11-Year-Old Children in 2003 were presented. Their positions taken in subsequent editions of the summer Polish championship till 2009 were the criterion of their career development. An analysis of documents was used as a scientific method. The basis for the analysis were post-competition protocols listed on the official website of the Polish Swimming Federation. Results. Only 30\% of the examined athletes took part in all main events intended for their age. Less than half of them participated in the Polish 17-18-Year-Old Junior Championships organized within the Nationwide Juvenile Olympics. 40\% of the girls from the studied group ended their careers before the age of 15 . Four basic variants of development of a sporting career were observed in the group. Conclusions. After analyzing the athletes' careers it can be stated that a high position in the national ranking of 11-year-olds does not guarantee significant sporting achievements in later years. In the studied group of girls the stroke and distance specialization had changed in most cases $(80 \%)$.
\end{abstract}

Key words: swimming, training, children, sporting career

\section{Introduction}

The Polish system of sports training in swimming for many years included the rivalry of ten and eleven-year-old children in a nationwide event, which was the regional Polish Correspondence Championship. It was assumed that the performance in this competition will be the first tangible test of skills acquired at the primary stage of training. Since the 2010/2011 season the Polish Correspondence Championships were replaced by the Nationwide 10 and 11-Year-Old Children Team Competitions, but the individual athletes' classification had been preserved. Children who are ranked $1^{\text {st }}$ to $20^{\text {th }}$ in the nationwide scale can boast of defeating hundreds of their rivals, so their sporting achievements can be objectively assessed as very high. However, these athletes' subsequent careers were not always related to such a high sporting achievement as in their childhood. Even at a passing glance at the list of winners in the main swimming competitions addressed for 10 and 11-year-old children - regardless of stroke and distance - reveals the lack of these names in the reports of the Polish junior championships of 16-year-olds and older. Thus, there are some reasons for which juvenile masters do not maintain a high level of their sporting achievements at successive stages of their careers.

The course of a sporting career should be gradual and result from proper training at various stages of young athlete's development. According to Sozański [1], the following objectives should be implemented at successive stages of sports training:

- age 10 years - developing interests, fun and joy, the acquisition of basic motor skills,

- age 11-14 years - versatility, mastering the technique, preparing for a progressive workout,

- age 15-18 years - progressive training, specialized training (introduction), adaptation to a large number of starts.

Based on the analysis of training loads applied for many years to athletes who acquired the mastery level in swimming, Sachnowski and Sozański [2] identified four basic variants of reaching the maximal sport achievements.

Variant 1, the traditional one, assumed to reach the champion level by men aged 18-22 years and women aged $17-20$ years after 8-10 and 7-9 years of training, respectively.

Variant 2 led to achieving maximal results at the age of 13-16 years for women and 16-18 years for men after 6-8 years of training. This variant was characterized by a rapid (and often irregular) increase in sporting achievements at the mastery level. Application of training loads in this variant was more dynamic; therefore, at the stage of orientated training an athlete performed a workout of about $50 \%$ of the amount typical of the maximal performance stage.

Variant 3, the moderate one, enabled reaching the maximal results by male sprinters aged 23-26 years, and long-distance swimmers aged 21-23 years. Female sprinters achieved maxi- 
mal results at the age of 21-25, and long-distance swimmers at the age of 19-21. This solution was characterized by the extension of the athlete's preparation time to 12-15 years. The slow pace of achieving mastery level, typical of this variant, was probably caused by a delay in entering the phase of biological maturity.

Variant 4 was characteristic of sprinters who started their competitive swimming training late (e.g. at the age of 14). The high level of motor skills needed in sprint swimming was formed in these athletes while practicing other sports. This option would lead to the level of the highest sporting achievements in swimmers aged 19-22 years, after 5-6 years of training.

Analyzing the course of modern careers in competitive swimming, it can be concluded that variants 1 and 2 are still the most frequently applied. Ryan Lochte, Pawel Korzeniowski and Kristy Coventry achieved the world-top sport levels after their $20^{\text {th }}$ birthday. Kosuke Kitajima and Michael Phelps took part in the finals of the Olympic Games as teenagers, but their careers are still developing. Ian Thorpe became the world champion at the age of 15 and then remained one of the best world middle distance crawl swimmers for many years. A typical "by leaps" career development may be demonstrated by a Hungarian swimmer Daniel Gyurta, who won a silver medal at the age of 15 during the 2004 Olympic Games, then disappeared from top swimming rankings for a few seasons and returned in 2009, reaching for the world champion title. German athlete Franziska van Almsick had a similarly uneven career. As a 14-year-old she won her first individual Olympic medal, two years later set a world record, and after seven years of apparent decline in sporting achievements, she re-established a world record. According to experts, a high level of sports performance achieved by teenagers can be explained by two major factors: an appropriate body posture and a perfect swimming technique. Laszlo Kiss [3], the coach of the Olympic champion Krisztina Egerszegi, described her body shape at the age of 12 as ideal for backstroke: slim thighs, broad shoulders, big palms, great flexibility of shoulder joints and excellent buoyancy. According to coach David Salo, Kosuke Kitajima - a multiple world champion and an Olympic champion - did not stand out in ideal body shape, but his greatest asset was the perfect technique. In the case of this athlete, extraordinary flexibility of the ankle joints increased the effectiveness of leg movements in breaststroke, while adopting a streamlined position in the water almost completely reduced the water drag [4]. In the first decade of the $21^{\text {st }}$ century a clear trend to extend the period of stabilization of the mastery achievements can be seen. This phenomenon refers to the swimmers who won their first medals in the European or world championships after reaching adulthood. Therefore, it is a reference to the third variant, proposed by Sachnowski and Sozański. Therese Alshammar, Thomas Rupprath, Mark Foster and Martina Moravcowa at the age of 30 were winning in international competitions against rivals younger by 10-12 years. It should be noted that this trend applies only to sprint events mainly $50 \mathrm{~m}$. Mature athletes are characterized by mastering the performance of the technical elements of a swimming racejump start and turns, as well as an appropriate mental preparation, which is a very important part of the strategy for shortdistance races. Motor preparation of these athletes is mainly based on strength and speed. The American Dara Torres, who won a silver Olympic medal at the age of 41, is a spectacular example of a "veteran" among top-class swimmers. It was her greatest individual achievement, as in some previous Olympics Games, she won gold medals in relay events.

The course of a sporting career is conditioned by the development of individual results. As noted above, the dynamics of an increase in the results rate has no uniform, universal character. Attempts to identify the factors that determine the sports progress in juvenile swimmers are undertaken. Wojciechowski and Wagner [5] evaluated the sport level of female swimmers in groups from 11 to 17 years of age, based on the results of two events: $100 \mathrm{~m}$ freestyle and $100 \mathrm{~m}$ breaststroke. A ranking list published by the Polish Swimming Federation was the source of the analysis. It was found that the largest variability of the results are related to the swimmers at the age of 13-16. It was also observed that the number of older competitors was decreasing systematically. For example, in 1997 in the $100 \mathrm{~m}$ freestyle event 128 athletes aged 13 years started officially compared to only 23 athletes aged 17 years. A team of Portuguese researchers studied the development of $200 \mathrm{~m}$ freestyle performance among 29 best national male swimmers. Results achieved in successive seven seasons, i.e. from 12 to 18 years of age were analyzed. The authors found a clear tendency to stabilize the increase in results between 14 to 18 years of age. No significant difference in improving the results was observed in the age group 16-17 years and 17-18 years. The authors explain this phenomenon by several reasons, e.g. application of peak training loads, the depletion of physiological capabilities to the maximum effort given and the stagnation in the development of anthropometric variables. According to the authors, the results achieved in this event between the $13^{\text {th }}$ and $14^{\text {th }}$ year of age provide a strong basis for predicting the results achieved in later years [6]. Watanabe and Takai [7] analyzed the correlation between the results achieved in the $50 \mathrm{~m}$ freestyle event and the four factors: body size, muscle strength, flexibility and efficiency of swimming technique. The researchers examined 114 boys and 130 girls aged 8-18 years, who trained swimming competitively. Results suggest that the swimming technique is the strongest determinant of sports performance in girls and boys under 14 years of age. In older girls sports results correlated the most strongly with body size, while in boys with muscular strength. The authors recommend working on the proper swimming technique in younger athletes, as it constitutes the basis for the development of results in later stages of their careers. Similar observations were presented by Garrett and Kirkendall [8]. Their research carried out on a group of 25 Canadian teenage swimmers indicated that body height was highly correlated with the results achieved in the $100 \mathrm{~m}$ freestyle. In a distance of $400 \mathrm{~m}$ freestyle the best result were obtained by athletes presenting the highest value of stroke rate.

The purpose of this study was to find the association between the sports performance of 11-year-old girls and their sports level in consecutive years of their careers. The following research questions were asked:

1. Did the girls presenting the highest national sports level at the age of 11 continue their career at a similar level?

2. Did the 11-year-old girls achieving the best national results in the $200 \mathrm{~m}$ backstroke present a high sports level in this event also in the subsequent years?

3. What percentage of the nation's best 11-year-old girls in the $200 \mathrm{~m}$ backstroke continued their career to the age of $17-18$ ?

\section{Material and methods}

The results of twenty 11-year-old girls classified highly in the $200 \mathrm{~m}$ backstroke event at the Polish 10 and 11-Years-Old Children Correspondence Championships in 2003 were analyzed. The girls' careers in subsequent years (2004-2009) were evaluated on the basis of the results achieved at the Polish summer championships. An analysis of documents was used as a scientific method. The analysis of the results was made according to the protocols listed on the official website of the Polish Swimming Federation (www.polswim.pl). The study 
included results of the events, where athletes have been reported regularly. Results of the events in which the athlete competed rarely or only once, were omitted from this study. Data were prepared graphically based on Excel 2000.

\section{Results}

Table 1 presents the participation of the $200 \mathrm{~m}$ backstroke finalists at the Polish Correspondence Championships of 10 and 11-Years-Old Children in the consecutive editions of the Polish championships. Only 30\% of athletes took part in all the main events intended for their age. Less than half of them participated in the Polish 17-18-Year-Old Junior Championships known as the Nationwide Juvenile Olympics.

Table 1. Participation of the finalists of the $200 \mathrm{~m}$ backstroke event at Polish Correspondence Championships of 10 and 11-years-old Children in the subsequent editions of Polish championships

\begin{tabular}{|c|c|c|c|c|c|c|c|c|}
\hline No. & Athlete & $\begin{array}{c}10-11-y r s \\
\text {-old } \\
\text { corresp. } \\
\text { champs } \\
2003\end{array}$ & $\begin{array}{l}\text { 12-yrs } \\
\text {-old } \\
\text { champs, } \\
\text { Dębica } \\
2004\end{array}$ & $\begin{array}{c}\text { 13-yrs } \\
\text {-old } \\
\text { champs, } \\
\text { Oświęcim } \\
2005\end{array}$ & $\begin{array}{c}14-y r s \\
\text {-old } \\
\text { champs, } \\
\text { Gdynia } \\
2006\end{array}$ & $\begin{array}{c}15 \cdot y r s \\
\text { old } \\
\text { champs, } \\
\text { Lódz } \\
2007\end{array}$ & $\begin{array}{l}\text { 16-yrs } \\
\text { old } \\
\text { champs, } \\
\text { Dębica } \\
2008\end{array}$ & $\begin{array}{l}\text { 17-18-yrs } \\
\text { old } \\
\text { champs, } \\
\text { Oświęcim } \\
2003\end{array}$ \\
\hline 1 & A & $x$ & $x$ & $X$ & $x$ & $X$ & $X$ & $X$ \\
\hline 2 & B & $X$ & $X$ & $x$ & $x$ & $x$ & $X$ & $X$ \\
\hline 3 & C & $x$ & $x$ & & $x$ & $x$ & $x$ & $x$ \\
\hline 4 & D & $x$ & & & & & & \\
\hline 5 & $\mathbf{E}$ & $x$ & & $x$ & $x$ & $x$ & $X$ & \\
\hline 6 & $F$ & $x$ & $x$ & $X$ & $X$ & $x$ & $X$ & $X$ \\
\hline 7 & $\mathbf{G}$ & $x$ & $x$ & $x$ & $x$ & $x$ & & \\
\hline 8 & H & $x$ & & $X$ & $x$ & $x$ & $X$ & $x$ \\
\hline 9 & $I$ & $X$ & $x$ & $x$ & $x$ & $x$ & $x$ & \\
\hline 10 & $\mathbf{J}$ & $X$ & $x$ & $X$ & $x$ & & & \\
\hline 11 & K & $x$ & & & & & & \\
\hline 12 & $\mathbf{L}$ & $x$ & $x$ & $x$ & $x$ & $x$ & $x$ & $x$ \\
\hline 13 & $M$ & $X$ & & & & & & \\
\hline 14 & $\mathbf{N}$ & $x$ & $X$ & $X$ & $x$ & $X$ & $x$ & $X$ \\
\hline 15 & 0 & $x$ & $X$ & $x$ & $x$ & & & \\
\hline 16 & $\mathbf{P}$ & $x$ & $x$ & $x$ & $x$ & $x$ & & \\
\hline 17 & $\mathbf{R}$ & $x$ & $x$ & $x$ & $x$ & & $x$ & $x$ \\
\hline 18 & $S$ & $X$ & $X$ & $X$ & & $x$ & $x$ & \\
\hline 19 & $\mathbf{T}$ & $x$ & $x$ & & & & & \\
\hline 20 & $\mathbf{U}$ & $x$ & $x$ & $x$ & $x$ & $x$ & $X$ & $x$ \\
\hline
\end{tabular}

Eight athletes (40\%) out of twenty finalists of the $200 \mathrm{~m}$ backstroke event at the Polish Correspondence Championships of 10 and 11-Years-Old Children continued their careers in later years at a high level, that is taking place in finals A of the Polish championships.

After a detailed analysis of the career of each of the twenty athletes, four variants of reaching sporting achievement can be specified.

Variant 1 applies to "wonder children", that is athletes who have achieved the greatest sport successes at the beginning of their careers. Athletes "G" and "P" can be used in this variant as an example (Fig. 1). The greatest achievements - medal places - were noted in " $G$ " only in 2002 , when she was 10-yearsold. In the later years of her career, the results in the $200 \mathrm{~m}$ backstroke event varied from the $7^{\text {th }}$ place to the $15^{\text {th }}$. As a 15year-old girl, "G" was placed outside the A finals in the $100 \mathrm{~m}$ and $200 \mathrm{~m}$ backstroke events, which may have contributed to the end of her career. On the other hand, "P" took the first place in the national ranking at the age of 11 and for the next two years achieved high positions in the $100 \mathrm{~m}$ butterfly. At the age of 14 she lost her high-ranked positions and reached the results which placed her in the B finals. The year 2006 brought even poorer performances in her crowned event of the $100 \mathrm{~m}$ butterfly. The attempts to compete in other distances and events did not bring the expected success. After the year 2006, "P" did not compete in the Polish championships.

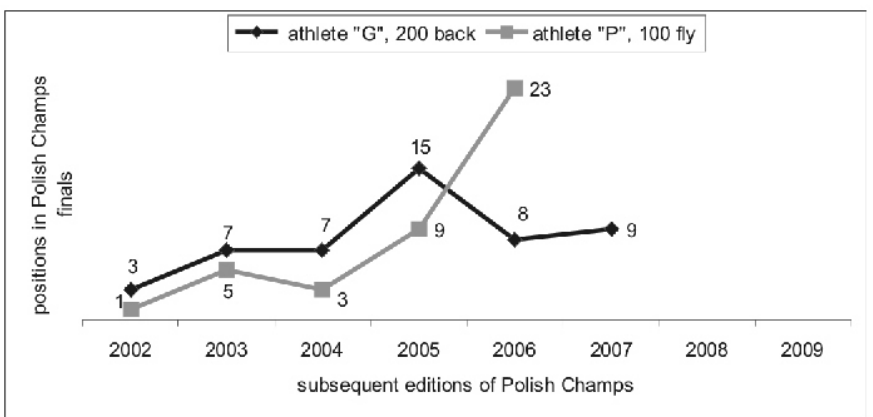

Figure 1. Variant 1 of a career of 11-year-old swimmers - the highest sports achievements in childhood, based on examples of athletes "G" and "P"

Variant 2 includes the careers of the girls who maintained top positions in their age category for many seasons. The high level of sports achievement was associated, among others, with a change in stroke specialization. Such a situation can be seen in athletes "A" and "F" (Fig. 2). Athlete "A", in addition to excellent results in the $200 \mathrm{~m}$ backstroke at the age of 11, occupied the top places in the country in the $50 \mathrm{~m}$ freestyle and $100 \mathrm{~m}$ backstroke. By the year 2008 a stable course of her sporting achievements can be observed; she kept her position in the national forefront. The year 2005 proved to be the most beneficial in her career when she won three gold medals at one Polish championships (100 $\mathrm{m}$ freestyle event is not included in the figure). In later years, "A" did not compete in backstroke events regularly, focusing on freestyle events, mainly $100 \mathrm{~m}$ and $200 \mathrm{~m}$. The year 2009 brought a clearly undesirable change in the athlete's career, as she was classified outside the podium. Swimmer "F" is also an example of a stable career, because the achieved results placed her highly at the national level for many years. As shown in Figure 2, the athlete gave up her specialization in the backstroke quickly, focusing on the medley stroke in the later years of her career. The year 2007 proved to be extremely unfortunate if compared to the previous seasons, but the results achieved in 2008 and 2009 confirmed a high position of " $F$ " among peers specializing in the medley stroke.

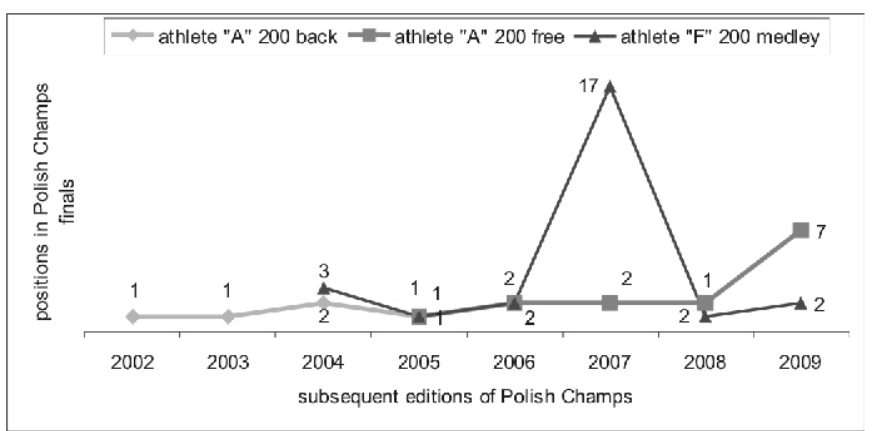

Figure 2. Variant 2 of a career of 11-year-old swimmers - long-term high level of sports achievements, based on examples of athletes "A" and " $F$ " 
Variant 3 is associated with a short-term career in sport, without significant successes. This variant can be described based on the examples of athletes "J" and "O" (Fig. 3). After being placed $10^{\text {th }}$ in the $200 \mathrm{~m}$ backstroke event among 11-year-olds, "J" took fourth location in this event a year later. The athlete and her coach will probably keep the secret, why the performance in this event was not continued in subsequent years. Her debut in the freestyle events in 2005 ranked the athlete on the border between finals $\mathrm{A}$ and $\mathrm{B}$. The following year brought a significant deterioration in the results of the $200 \mathrm{~m}$ freestyle, after that performance the career of "J" ended prematurely. The performance of the 11-year-old "O" in the $200 \mathrm{~m}$ backstroke event was unique, as in the following seasons she preferred the freestyle. In 2005, swimmer "O" improved her ranking positions in the $200 \mathrm{~m}$ and $400 \mathrm{~m}$ freestyle events in comparison with the previous year (400 $\mathrm{m}$ freestyle was not included in the figure). However, her participation in the Polish championships in 2006 resulted below the $20^{\text {th }}$ place in $200 \mathrm{~m}$ and $400 \mathrm{~m}$ freestyle. This could influenced her decision to end the career in swimming.

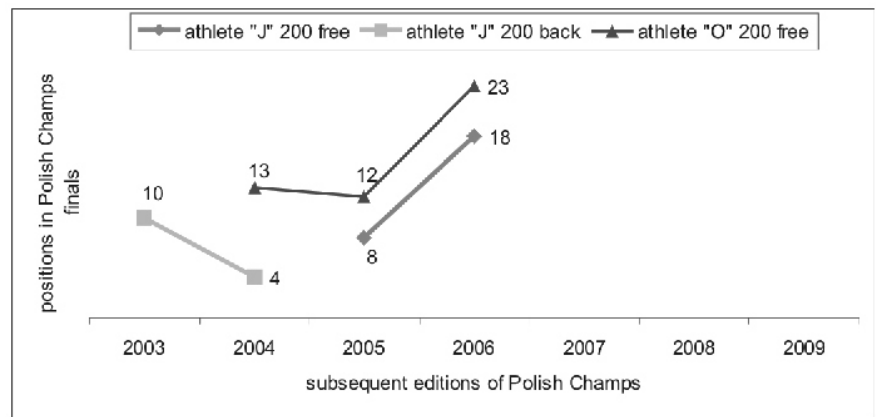

Figure 3. Variant 3 of a career of 11-year-old swimmers - short-term career without the significant successes, based on example of athletes "J" and "O"

Variant 4 is associated with a long-term career characterized by a systematic increase in the sport achievements. As an example, in athlete "U" a systematic improvement in the backstroke events results from the category of 11-year-old child to a 17-18year-old junior can be observed (Fig. 4). The most successful performance occurred during the Polish 16-Year-Old Junior Championship, where she won two bronze medals. A year later, despite the improvement of achieved results, she was not able to stand on the podium at the Polish championships. It is noteworthy that very titled peers of "U" competed also in the backstroke events that year. These girls often gained medals in international competitions and Polish senior championships.

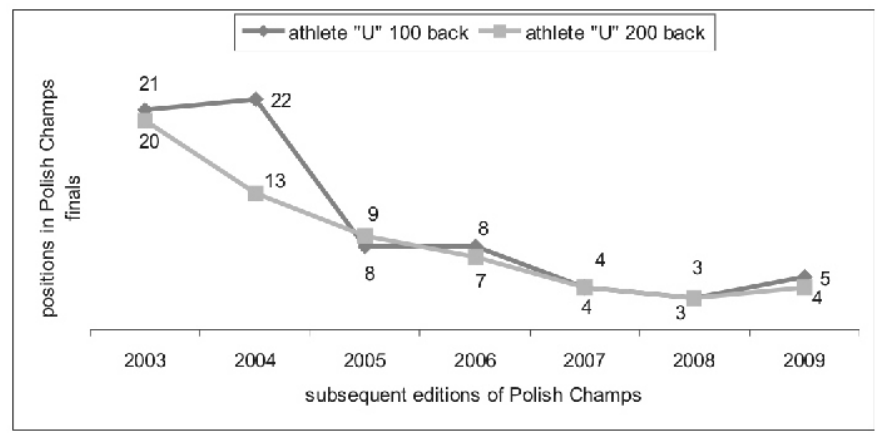

Figure 4. Variant 4 of a career of 11-year-old swimmers - high sports achievements gained in later stages of career, based on example of athlete " $U$ "
An additional fifth variant is not so much a "career interrupted", but "career not initiated". For example, athletes "D", "K", "M" and "T" can be seen to abandon interest in competitive swimming already in their childhood (Tab. 1). It seems that the decision to discontinue their swimming training had no sportrelated background in these cases. As stated previously, the placement in the top twenty nationwide ranking of 11-year-old swimmers proofs a high level of sports achievements.

\section{Discussion}

The analysis presented above inspires to reflect on issues of the very young athletes' sports career. Out of the twenty best Polish 11-year-old girls competing in the $200 \mathrm{~m}$ backstroke event, eight ended their sports career before their $15^{\text {th }}$ birthday. It seems that this is a big number, especially in the context of the potential in furthering the advantages of the girls' talent and involvement. It should be stated that in the children age category hundreds of athletes compete in each event, therefore, qualification to the top twenty nationwide ranking is a great achievement. Abandonment of a promising career arouses presumptions and speculations. The results of a long term research conducted in Brazil among young judoists showed that only a few percent of athletes presenting master level as teenagers, achieved that level in the senior category [9].

According to Stambułowa [10], there are usually three types of crises in sports activities. They are associated with:

- age - career may facilitate the maturity process, helping teens to gain popularity, but it may also be detrimental because of the physical and psychological changes that affect the training,

- changes in the training stage - early sports specialization, taking the intensive training in a chosen discipline, the transition to the "adult sport" phase and entering the highest sports achievements,

- specific situations - in the areas of the training process, participation in competitions and circumstances of life, affecting the sports career.

Groenwald-Luty [11] observed in the $3^{\text {rd }}$ grade primary school children have a very strong emotional involvement in training, especially in a competition performance. In the children's opinion that success is the element in a potential future sports career and the prestige associated with practicing a competitive sport, while defeat means the abandonment of all the dreams and aspirations connected with a sporting career. A survey conducted among the children's parents revealed that expectations of belonging to the sport class were mainly associated with the harmonious combination of school education, sport training and the involvement in other school activities. Parents of children, standing on the threshold of their sporting career, were afraid mainly of the inability to reconcile the sport training and school education, injuries and illnesses preventing children from continuing their sports careers. Interviewed parents also became concerned about the children's lack of motivation to workout and the lack of sufficient abilities for competitive swimming.

The results of the research conducted in former athletes practicing individual sports have shown that the most common reasons for the abandonment of their careers are lack of prospects for promotion in sports career, health considerations, the conflict between the social roles (employee, parent) and the athlete role. The athletes also left their sports practice due to conflicts with the coach and because of a sense of underestimation [12]. The lack of prospects in sports development seem to be a likely reason for giving up the career of those girls who achieved top places in nationwide rankings at the age of 10-11, 
and in subsequent years were steadily losing the status of leaders. Perhaps this situation was caused by accelerated biological development of these girls, so that the level of their motor skills turned out to be higher than the rest of their rivals at this time. After a few years, their counterparts began to match the young masters in respect of biological development and sport performance. It is possible that the loss of their prestigious positions in the Polish championship finals may have weakened their motivation as athletes to hard work training. According to a study performed by Spanish scientists, children attach great importance to a cheerful and friendly atmosphere during their training, they want to do their best in competitions and they care about prestige resulting from sports achievements [13]. Regardless of motivation, reasons of deterioration in athletic performance could have been associated also with completely different spheres of the young female swimmers' life: educational problems, health problems, improperly conducted training. The system of training in swimming is based on the sports classification for many years. The main task of this classification is to assess progress in the athlete's career. The results of comparative analyzes indicate a high level of requirements set by the Polish Swimming Federation to the younger swimmers when compared to other Eastern Europe countries [14]. It is possible that some coaches use the raised training loads in the category for children, to meet the demands of classification. This training methodology can not be continued forever, as a young organism would finally cease to tolerate excessive loads [15]. Perhaps the general effect of the applied training loads was the reason of career's collapse in the case of some girls. From the perspective of a longterm sports training it is inadvisable to burden inappropriately (physically and mentally) children who are just starting a career. The aim of training at the orientated stage is the comprehensive development and improvement of swimming technique, therefore, the sports result should not be treated as a priority during this period.

The precise knowledge about the reasons of giving up a sports career requires extensive research on many areas of an athletes' life. It seems that the interviews with the swimmers and their coaches, parents and teachers would allow to see a career development and its accompanying obstacles more clearly. Perhaps a broader analysis of this phenomenon, including for example psychological profile of the athletes, would allow to recognize the factors influencing the career of young female swimmers more reliable.

\section{Conclusions}

On the basis of analysis presented above the following conclusions can be made:

1. The high position of athletes in the national ranking of 11-year-olds did not guarantee significant sport achievements in later years.

2. Stroke and distance specialization of 11-year-old girls was usually not continued on the subsequent stages of their careers.

3. Less than half of the national best 11-year-old athletes continued their sports career to 17 years of age.

\section{Literature}

1. Sozański, H. (1999). Foundations of Sport Training Theory. Warszawa: Wyd. RCMSzKFiS. [in Polish]

2. Sachnowski, K. \& Sozański H. (2000). Development of sports career, structure of the long-term training process. In W.N. Płatonow \& H. Sozański (Eds.), Optimalization of sports training structure (pp. 21-97). Warszawa: Wyd. RCMSzKFiS. [in Polish]

3. Kiss, L. (2008). Development of a world champion backstroker. American Swimming Magazine 6, 30-35.

4. Lohn, J. (2011). Swimming under the radar. Swimming World 1, 18-19.

5. Wojciechowski, P. \& Wagner W. (2000). Assessment of female swimmers sports level according to chosen events and age groups. In P. Kowalski, J. Migasiewcz \& K. Zatoń (Eds.), Swimming and track and field at school (pp. 217-222).Wrocław: Wyd. AWF Wrocław. [in Polish]

6. Costa, M.J., Bragada J.A., Marinho D.A., Reis V.M., Silva A.J. \& Barbosa T.M. (2010). Longitudinal assessment of swimming performance in the 200-m freestyle event. Open Sports Sci. J. 3, 92-94.

7. Watanabe, M. \& Takai S. (2005). Age-related change of the factors affecting swimming performance in junior swimmers. Jpn. J. Phys. Fitness Sports Med. 54(5), 353-361.

8. Garret, W.E. \& Kirkendall D.T. (2000). Exercise and sport science. Philadelphia: Lippincott Williams and Wilkins.

9. Julio, U.F., Takito M.Y., Mazzei L., Miarka B., Sterkowicz S. \& Franchini E. (2011). Tracking 10-year competitive winning performance of judo athletes across age groups. Percept. Mot. Skills 113(1), 139-149.

10. Stambułowa, N.B. (1998). How to counteract the crises in sports career. Sport Wyczynowy 5/6, 73-79. [in Polish]

11. Groenwald-Luty, E. (2001). On the threshold of sports career. Życie Szkoły 8, 480-482. [in Polish]

12. Litwiniuk, A. (1999). Resignation from sports career in the opinions of individual and team athletes. Rocznik Naukowy AWF Biała Podlaska 6, 59-66. [in Polish]

13. Salugero, A., Gonzalez-Boto R., Tuero C. \& Marquez S. (2003). Development of Spanish version of the participation motivation inventory for young competitive swimmers. Percept. Mot. Skills 96(2), 637-646.

14. Stanula, A. (2000). Comparative analysis of swimming training strategy according to the stucture of sports categories in Poland, Russia, Ukraine and Belarus. In P. Kowalski, J. Migasiewcz \& K. Zatoń (Eds.), Swimming and track and field at school (pp. 189-196). Wrocław: Wyd. AWF. [in Polish]

15. Bartkowiak, E. (1997). Swimming - teaching programme for children and adolescents. Warszawa: Wyd. RCMSzKFiS. [in Polish]

Submitted: November 10, 2011

Accepted:December 12, 2011 